\title{
Depression, body mass index, and chronic obstructive pulmonary disease - a holistic approach
}

This article was published in the following Dove Press journal:

International Journal of COPD

4 February 2016

Number of times this article has been viewed

\author{
Giuseppe Catalfo' \\ Luciana Crea' \\ Tiziana Lo Castro' \\ Francesca Magnano San Lio' \\ Giuseppe Minutolo' \\ Gherardo Siscaro ${ }^{2}$ \\ Noemi Vaccino' \\ Nunzio Crimi ${ }^{3}$ \\ Eugenio Aguglia' \\ 'Department of Psychiatry, Policlinico \\ "G. Rodolico" University Hospital, \\ University of Catania, Catania, Italy; \\ ${ }^{2}$ Operative Unit Neurorehabilitation, \\ IRCCS Fondazione Salvatore Maugeri, \\ Sciacca, Italy; ${ }^{3}$ Department of \\ Pneumology, Policlinico "G. Rodolico" \\ University Hospital, University of \\ Catania, Catania, Italy
}

Background: Several clinical studies suggest common underlying pathogenetic mechanisms of COPD and depressive/anxiety disorders. We aim to evaluate psychopathological and physical effects of aerobic exercise, proposed in the context of pulmonary rehabilitation, in a sample of COPD patients, through the correlation of some psychopathological variables and physical/ pneumological parameters.

Methods: Fifty-two consecutive subjects were enrolled. At baseline, the sample was divided into two subgroups consisting of 38 depression-positive and 14 depression-negative subjects according to the Hamilton Depression Rating Scale (HAM-D). After the rehabilitation treatment, we compared psychometric and physical examinations between the two groups.

Results: The differences after the rehabilitation program in all assessed parameters demonstrated a significant improvement in psychiatric and pneumological conditions. The reduction of BMI was significantly correlated with fat mass but only in the depression-positive patients.

Conclusion: Our results suggest that pulmonary rehabilitation improves depressive and anxiety symptoms in COPD. This improvement is significantly related to the reduction of fat mass and BMI only in depressed COPD patients, in whom these parameters were related at baseline. These findings suggest that depressed COPD patients could benefit from a rehabilitation program in the context of a multidisciplinary approach.

Keywords: COPD, depression, aerobic exercise, BMI

\section{Introduction}

According to the World Health Organization (WHO), depression was ranked as the third leading cause of the global burden of disease in 2004 and will move into the first place by 2030. Worldwide, the fifth contributor to the burden of disease in 2020 is predicted to be COPD. ${ }^{1,2}$

As defined by American Thoracic Society (ATS) and European Respiratory Society (ERS), COPD is a preventable and treatable disease state characterized by airflow limitation that is not fully reversible. The airflow limitation is usually progressive and is associated with an abnormal inflammatory response of the lungs to noxious particles or gases, primarily caused by cigarette smoking. It consists of the association of chronic bronchitis and emphysema. Chronic bronchitis is defined clinically as chronic productive cough for 3 months in each of 2 successive years in a patient in whom other causes of productive chronic cough have been excluded. Emphysema is defined pathologically as the presence of permanent enlargement of the airspaces distal to the terminal bronchioles, accompanied by destruction of their walls and without obvious fibrosis. ${ }^{3}$
Correspondence: Giuseppe Catalfo "G. Rodolico" University Hospital, University of Catania, Via S Sofia 78 95124, Catania, Italy

Tel +39095 3782470

$\mathrm{Fax}+390953782470$

Email giuseppecatalfo@gmail.com 
Several clinical studies show high rates of anxiety $(21 \%-96 \%)^{4}$ and affective (mostly depressive) disorders (27\%-79\%) in COPD, ${ }^{5,6}$ which can affect prognostic evolution in terms of compliance, disability, and mortality. ${ }^{7}$ It is not easy to diagnose depression in COPD patients because of overlapping symptoms between COPD and depression. Severe COPD could lead to somatic symptoms that are difficult to distinguish from depressive symptoms: eg, change in appetite/weight versus tearfulness/depressed appearance; sleep disturbances versus social withdrawal; fatigue or loss of energy versus brooding/pessimism; and diminished ability to think or concentrate versus lack of reactivity to environmental events. The validity of the International Classification of Diseases (ICD)-10 and Diagnostic and Statistical Manual of Mental Disorders (DSM)-5 criteria for depression, in fact, may to a certain degree be questioned, because it is difficult to decide when somatic symptoms are secondary to depression and when they are secondary to COPD. ${ }^{8}$ Additional variables that have potential to confound the association between COPD and depression regard some common risk factors, including the subject's demographic characteristics (age, sex, race/ethnicity, and marital status), education, body mass index (BMI), alcohol consumption, tobacco use, socioeconomic status (income), respiratory symptoms (dyspnea and difficulty with walking), and comorbid chronic conditions such as heart disease, stroke, diabetes, arthritis, hypertension, congestive heart failure, and cancer. ${ }^{9}$

The nature of the relationship between COPD and depression is not clear. However, it is well documented that depressed patients show a markedly elevated rate of cigarette smoking, ${ }^{10}$ which is the most important risk factor for COPD. It has been also postulated that (mild) hypoxia - that is also present in COPD patients - can induce central neurobiological changes that predispose to depression and suicide. ${ }^{11}$ Furthermore, in a study with a large sample, a relevant percentage of COPD patients entering pulmonary rehabilitation experienced clinically relevant symptoms of anxiety and depression. ${ }^{12}$

However, it could be supposed that both COPD and depression are the clinical manifestations of a common underlying pathophysiologic process. Indeed, data in the literature show that COPD and depression might not be "comorbid" conditions per se, but rather both are pathophysiologically related with a common substrate. ${ }^{13-26}$

Some authors suggest considering COPD as a "chronic systemic inflammatory syndrome" rather than a respiratory disease associated with extrapulmonary symptoms (including neurocognitive deficits, depression, anxiety, sleep disturbance, and other non-mental chronic disorders, such as coronary and peripheral artery diseases, anemia, osteoporosis, and rheumatoid arthritis). ${ }^{14}$

Some characteristics commonly observed in COPD patients, like obesity, ${ }^{27}$ are indeed associated with inflammation processes related to depression and anxiety, ${ }^{28}$ suggesting a complex bidirectional association between adiposity and depression. ${ }^{26}$ In this field, as suggested by some authors, the reduction of adiposity through physical exercise seems related to significant changes in depressive symptoms. ${ }^{29}$ As a consequence, ATS and ERS guidelines have emphasized the importance of pulmonary rehabilitation for patients with COPD. ${ }^{30}$

Several authors have indeed shown that there is a strong correlation among physical activity, adiposity, and mental health: several data have suggested that aerobic exercise shows significant effects, comparable to pharmacotherapy ${ }^{31-33}$ and to psychotherapy, ${ }^{34}$ on reducing depressive symptomatology. ${ }^{35}$

Coventry et al specifically demonstrated that structured exercise training significantly reduces both symptoms of depression and anxiety in people with COPD; furthermore, they showed that structured exercise training is more effective than other, complex psychological, behavioral and lifestyle interventions previously thought to improve mental health in people with COPD. ${ }^{36}$

Pulmonary rehabilitation shows poor effects on lung physiology (eg, ventilation parameters); nevertheless, it improves dyspnea, performance, anxiety, depressive symptoms, and quality of life (QoL). ${ }^{37-42}$ It also seems to decrease secretory function of adipocytes, resulting in reduction of their volume measured through fat mass. ${ }^{43}$ In this regard, although BMI is widely used as an indirect parameter to assess adiposity, it has been demonstrated that BMI would have a poor correlation with fat mass, which probably represents a more accurate measure. ${ }^{43}$

Considering the impact of aerobic exercise on anxious and depressive symptomatology, physical performance, QoL, and adiposity (assessed with BMI and fat mass), the primary aim of this study was to evaluate the effects of aerobic exercise, proposed in the context of pulmonary rehabilitation, through the correlation of psychopathological variables (depressive and anxious symptoms) and physical/ pneumological parameters. The secondary endpoint regards the evaluation of potential improvement in QoL and in cognitive performance. 


\section{Materials and methods}

This prospective cohort study was carried out in pneumology and psychiatry wards in the University Hospital PoliclinicoVittorio Emanuele of Catania, Italy from January to June 2012. The study was approved by the local ethical committee of the Policlinico "G. Rodolico" University Hospital, in accordance with the code of ethics of the World Medical Association, and written informed consent was obtained by all participants.

Inclusion criteria were diagnosis of COPD and eligibility to perform pulmonary rehabilitation, according to ATS and ERS guidelines. ${ }^{44}$

Exclusion criteria were indication for restoring treatment of airway patency and current psychopharmacological treatment (including sleeping pills).

Fifty-two consecutive subjects (46 males and six females) were enrolled, with a mean age of $71.5 \pm 6.29$ years and a mean school education of $8.08 \pm 3.21$ years.

Enrolled patients started a 6-week rehabilitation protocol, consisting of lower limb/limbs (treadmill and exercise bike) and upper art (arm ergometer Davenbike ${ }^{\circledR}$ ) training, as well as calisthenic exercises with increasing intensity from a minimum of $80 \%$ to a maximum workload for lower arts in a minimum time.

As proposed by the lung specialists in the pneumology ward of our university hospital, training sessions went on for 2 hours over 5 days a week and were supervised by two physiotherapists and a lung specialist. To exclude potential bias, no change in diet regime was carried out during the full duration of the trial.

Patients were evaluated at first access to pulmonary rehabilitation outpatient wards in order to assess inclusion and exclusion criteria.

For eligible patients, psychometric assessment, completion of the preliminary investigation, and admission in the rehabilitation program were performed. The assessment, measured both at baseline and at the end of the 3-month rehabilitation program, consisted of spirometry with bronchodilator test, walking test (6-minute walk test [6MWT]), BMI, Medical Research Council (MRC) dyspnea scale, impedentiometry, motor and metabolic evaluation by SenseWear Armband (for 3 consecutive days), Hopkins Symptom Checklist 90 (SCL-90), Hamilton Depression Rating Scale (HAM-D), Hospital Anxiety and Depression Scale (subscale HADS-A for anxiety; subscale HADS-D for depression), and State-Trait Anxiety Inventory (STAI-1 and STAI-2). Cognitive functions were also evaluated using Raven's Colored Progressive Matrices (CPM), Rey Auditory Verbal Learning Test (RAVLT), Clock Drawing Test
(CDT), and Trail Making Test parts A, B, and BA (TMT-A, TMT-B, and TMT-BA).

According to the HAM-D score (cutoff $=8$ ), the total sample was divided into two subgroups: depression-positive (D) and depression-negative (ND) subjects.

Continuous variables were compared using the Student's $t$-test and the Mann-Whitney $U$-test. Correlations were evaluated using Spearman's coefficient. Categorical variables were compared by chi-square test. A two-tailed test was used to assess statistical significance; a $P$-value of $<0.05$ was considered significant and a $P$-value of $<0.01$ was considered highly significant. Statistical analysis was performed using the Intercooled Stata 8 for Windows software (StataCorp LP, College Station, TX, USA).

\section{Results}

The descriptive analysis of psychometric and pneumological parameters at baseline and at the end of the rehabilitation program (at the end of month 3 ) are presented in Table 1.

Data show that improvement in all pneumological and respiratory parameters was statistically significant, except for Tiffeneau index.

The sample was divided into two subgroups consisting of $38 \mathrm{D}$ and 14 ND subjects according to HAM-D.

The mean and standard deviation of psychometric and pneumological parameters at baseline and month 3 in both patient subgroups are shown in Table 2. We did not find a statically significant difference between the two subgroups in age, lung function, and baseline body composition.

Regarding the mean BMI at baseline, the D subgroup was overweight $(24 / 38$ patients, $=63 \%$, had a mean BMI $28.37 \pm 6.80)$ and the ND subgroup was normal weight (4/14 patients, $=28 \%$, had a mean BMI 24.96 \pm 4.1 ) (Figures 1 and 2), according to WHO criteria, ${ }^{45}$ even if the absolute difference in BMI between the two subgroups was not statistically significant. Pneumological and psychological parameters overlapped except for HAM-D $(P=0.002)$, HADS-A $(P=0.03)$, SCL-90 ( $P=0.02)$, and TMT-A $(P=0.02)$ : these differences disappeared at 3 months. At baseline $73 \%$ of subjects (38/52) exceeded the cutoff for depression on the HAM-D (D subgroup). At month 3, the rate of D subjects was reduced from $73 \%$ to $7.7 \%(4 / 52$, odds ratio $6.6, P=0.0002)$. The improvement in almost all other psychological and medical/ pneumological parameters was also significant both in the D and ND subgroups at the end of the study.

We compared reported differences following the rehabilitation treatment between the D and ND subgroups 
Table I Descriptive and paired comparison analysis of psychometric and pneumological parameters at baseline and at 3 months in the total sample of patients with COPD in a pulmonary rehabilitation program

\begin{tabular}{|c|c|c|c|c|c|c|c|}
\hline \multirow[t]{2}{*}{ Parameters } & \multicolumn{2}{|l|}{ Baseline } & \multicolumn{2}{|l|}{3 months } & \multicolumn{2}{|l|}{ Variations } & \multirow[t]{2}{*}{$P$-value } \\
\hline & Median & SD & Median & SD & Median & SD & \\
\hline HAM-D & $\mid 1.31$ & 6.31 & 3.88 & 3.70 & -7.42 & 5.99 & $<0.000$ I \\
\hline HADS-A & 5.73 & 2.38 & 2.54 & 2.04 & -3.19 & 2.58 & $<0.0001$ \\
\hline HADS-D & 8.15 & 3.91 & 3.19 & 2.54 & -4.96 & 3.26 & $<0.000$ I \\
\hline STAI-I & 40.73 & 9.00 & 30.50 & 6.09 & -10.23 & 9.27 & $<0.0001$ \\
\hline STAI-2 & 40.96 & 8.19 & 29.85 & 7.44 & -11.12 & 8.94 & $<0.000$ I \\
\hline SCL-90 & 0.72 & 0.31 & 0.30 & 0.22 & -0.42 & 0.28 & $<0.0001$ \\
\hline TMT-A & 67.73 & 22.32 & 54.50 & 14.65 & -13.23 & 21.24 & 0.0089 \\
\hline TMT-B & 200.40 & 81.68 & 132.50 & 49.86 & -67.88 & 65.89 & $<0.0001$ \\
\hline TMT-BA & 132.70 & 76.68 & 80.31 & 46.57 & -52.35 & 58.79 & 0.0002 \\
\hline RAVLT (immediate) & 39.69 & 8.71 & 47.65 & 8.83 & 7.96 & 5.63 & $<0.0001$ \\
\hline RAVLT (deferred) & 8.38 & 2.99 & 10.42 & 2.76 & 2.04 & 1.99 & $<0.000$ I \\
\hline CDT & 6.98 & 1.71 & 8.50 & 1.25 & 1.52 & 1.75 & 0.0005 \\
\hline CPM & 26.19 & 3.87 & 30.38 & 3.14 & 4.19 & 4.14 & 0.0001 \\
\hline $\mathrm{FVC}(\mathrm{L})$ & 2.67 & 0.73 & 3.01 & 0.80 & 0.33 & 0.30 & $<0.0001$ \\
\hline $\mathrm{FEV}_{1}(\mathrm{~L})$ & 1.49 & 0.63 & 1.66 & 0.63 & 0.18 & 0.19 & 0.0002 \\
\hline $\mathrm{FEV}_{1} / \mathrm{FVC}(\%)$ & 55.77 & 17.01 & 55.42 & 15.59 & 0.35 & 5.93 & ns \\
\hline SVC (L) & 3.00 & 0.83 & 3.27 & 0.84 & 0.28 & 0.31 & 0.0001 \\
\hline IC (L) & 2.02 & 0.76 & 2.38 & 0.69 & 0.37 & 0.49 & $<0.000$ I \\
\hline 6MWT (m) & 345.60 & 138.50 & 438.30 & 106.60 & 92.77 & 62.16 & $<0.000$ I \\
\hline BMI $\left(\mathrm{kg} / \mathrm{m}^{2}\right)$ & 27.46 & 6.29 & 26.52 & 6.02 & -0.93 & 0.79 & $<0.000$ I \\
\hline Fat mass (\%) & 27.38 & 8.07 & 26.44 & 7.53 & -0.94 & 0.74 & $<0.0001$ \\
\hline Steps/day & 10,196 & 8,439 & 13,260 & 9,100 & 3,064 & 2,490 & $<0.0001$ \\
\hline Energy expenditure (joules/3 days) & $11,376.296$ & $5,978.936$ & $13,141.944$ & $6,648.376$ & $\mathrm{I}, 768,576.8$ & $3,550,960.8$ & 0.0007 \\
\hline Physical activity duration (minutes) & 49.19 & 34.23 & 76.85 & 31.59 & 27.65 & 10.77 & $<0.0001$ \\
\hline MRC & 3.38 & 0.70 & 2.19 & 0.75 & -1.19 & 0.49 & $<0.0001$ \\
\hline BODE index & 10.00 & 2.87 & 7.69 & 2.17 & -2.31 & 1.44 & $<0.000$ I \\
\hline CAT & 19.96 & 3.65 & 15.46 & 3.40 & -4.50 & 1.77 & $<0.0001$ \\
\hline
\end{tabular}

Abbreviations: 6MWT, 6-minute walk test; BMI, body mass index; BODE, BMI, obstruction, dyspnea, exercise capacity; CAT, COPD Assessment Test; CDT, Clock Drawing Test; CPM, Colored Progressive Matrices; FEV , forced expiratory volume in the Ist second; FVC, forced vital capacity; HADS-A, Hospital Anxiety and Depression Scale, anxiety subscale; HADS-D, Hospital Anxiety and Depression Scale, depression subscale; HAM-D, Hamilton Depression Rating Scale; IC, inspiratory capacity; MRC, Medical Research Council; ns, nonsignificant; RAVLT, Rey Auditory Verbal Learning Test; SCL-90, Symptom Checklist 90; SD, standard deviation; STAI, State-Trait Anxiety Inventory; SVC, slow vital capacity; TMT, Trail Making Test.

Table 2 Descriptive and paired comparison analysis of psychometric and pneumological parameters at baseline and at 3 months in the depression-positive subgroup $(n=38)$ and the depression-negative subgroup $(n=14)$ of patients with COPD in a rehabilitation program

\begin{tabular}{|c|c|c|c|c|c|}
\hline \multirow[t]{2}{*}{ Parameters } & \multicolumn{2}{|l|}{ Baseline } & \multicolumn{2}{|c|}{3 months } & \multirow[t]{2}{*}{$P$-value } \\
\hline & Median & SD & Median & SD & \\
\hline \multicolumn{6}{|l|}{ HAM-D } \\
\hline Depressed & 13.68 & 5.61 & 4.68 & 3.81 & 0.0000 \\
\hline Nondepressed & 4.80 & 2.19 & 1.71 & 2.4 & 0.01 \\
\hline \multicolumn{6}{|l|}{ HADS-A } \\
\hline Depressed & 6.31 & 2.10 & 2.4 & 2.06 & 0.0000 \\
\hline Nondepressed & 4.14 & 2.47 & 2.71 & 2.13 & ns \\
\hline \multicolumn{6}{|l|}{ HADS-D } \\
\hline Depressed & 9 & 4.24 & 3.42 & 2.755 & 0.0000 \\
\hline Nondepressed & 5.85 & 1.21 & 2.57 & 1.90 & 0.01 \\
\hline \multicolumn{6}{|l|}{ STAI-I } \\
\hline Depressed & 41.89 & 10.20 & 31.21 & 6.42 & 0.0003 \\
\hline Nondepressed & 37.57 & 3.15 & 28.57 & 4.99 & 0.007 \\
\hline
\end{tabular}


Table 2 (Continued)

\begin{tabular}{|c|c|c|c|c|c|}
\hline \multirow[t]{2}{*}{ Parameters } & \multicolumn{2}{|l|}{ Baseline } & \multicolumn{2}{|l|}{3 months } & \multirow[t]{2}{*}{$P$-value } \\
\hline & Median & SD & Median & SD & \\
\hline \multicolumn{6}{|l|}{ STAI-2 } \\
\hline Depressed & 43.10 & 8.06 & 31.10 & 7.62 & 0.0000 \\
\hline Nondepressed & 35.14 & 5.52 & 26.42 & 6.16 & 0.01 \\
\hline \multicolumn{6}{|l|}{ SCL-90 } \\
\hline Depressed & 0.80 & 0.30 & 0.32 & 0.22 & 0.0000 \\
\hline Nondepressed & 0.49 & 0.18 & 0.25 & 0.07 & 0.01 \\
\hline \multicolumn{6}{|l|}{ TMT-A } \\
\hline Depressed & 68 & 24.59 & 56.10 & 15.90 & 0.03 \\
\hline Nondepressed & 67 & 16.11 & 50.14 & 10.23 & 0.05 \\
\hline \multicolumn{6}{|l|}{ TMT-B } \\
\hline Depressed & 202.36 & 87.74 & 139.15 & 51.25 & 0.0009 \\
\hline Nondepressed & 195 & 68.25 & II4.42 & 44.22 & 0.01 \\
\hline \multicolumn{6}{|l|}{ TMT-BA } \\
\hline Depressed & 134.36 & 82.56 & 85.15 & 47.67 & 0.002 \\
\hline Nondepressed & 128 & 63.36 & 67.14 & 44.02 & 0.02 \\
\hline \multicolumn{6}{|l|}{ RAVLT (immediate) } \\
\hline Depressed & 39.05 & 9.00 & 47.42 & 9.32 & 0.0000 \\
\hline Nondepressed & 41.42 & 8.24 & 48.24 & 7.93 & 0.049 \\
\hline \multicolumn{6}{|l|}{ RAVLT (deferred) } \\
\hline Depressed & 8.63 & 2.81 & 10.57 & 2.83 & 0.0003 \\
\hline Nondepressed & 7.71 & 3.59 & 10 & 2.7 & 0.04 \\
\hline \multicolumn{6}{|l|}{ CDT } \\
\hline Depressed & 7.13 & 1.57 & 8.73 & 1.17 & 0.0009 \\
\hline Nondepressed & 6.57 & 2.14 & 7.85 & 1.31 & ns \\
\hline \multicolumn{6}{|l|}{ CPM } \\
\hline Depressed & 26.89 & 3.64 & 31.10 & 2.99 & 0.0001 \\
\hline Nondepressed & 24.28 & 4.07 & 28.42 & 2.81 & ns \\
\hline \multicolumn{6}{|l|}{$\mathrm{FVC}(\mathrm{L})$} \\
\hline Depressed & 2.69 & 0.73 & 2.97 & 0.80 & 0.0003 \\
\hline Nondepressed & $2.6 I$ & 0.78 & 3.10 & 0.83 & 0.009 \\
\hline \multicolumn{6}{|l|}{$\mathrm{FEV}_{1}(\mathrm{~L})$} \\
\hline Depressed & 1.48 & 0.58 & 1.67 & 0.58 & 0.0009 \\
\hline Nondepressed & 1.49 & 0.80 & 1.61 & 0.77 & ns \\
\hline \multicolumn{6}{|l|}{$\mathrm{FEV}_{1} / \mathrm{FVC}(\%)$} \\
\hline Depressed & 55.94 & 17.58 & 56.89 & 15.88 & ns \\
\hline Nondepressed & 55.28 & 16.66 & 51.42 & 15.17 & ns \\
\hline \multicolumn{6}{|l|}{ SVC (L) } \\
\hline Depressed & 2.9 & 0.84 & 3.20 & 0.86 & 0.0008 \\
\hline Nondepressed & 3.26 & 0.76 & 3.44 & 0.81 & 0.007 \\
\hline IC (L) & & & & & \\
\hline Depressed & 2.0 & 0.62 & 2.29 & 0.70 & 0.0006 \\
\hline Nondepressed & 2.05 & 1.09 & 2.61 & 0.61 & ns \\
\hline 6MWT (m) & & & & & \\
\hline Depressed & 326.57 & 144.75 & 421.15 & II0.955| & 0.0000 \\
\hline Nondepressed & 397.14 & 113.38 & 485 & 83.16 & 0.01 \\
\hline BMI $\left(\mathrm{kg} / \mathrm{m}^{2}\right)$ & & & & & \\
\hline Depressed & 28.37 & 6.80 & 27.47 & 6.53 & 0.0001 \\
\hline Nondepressed & 24.96 & 4.01 & 23.94 & 3.50 & 0.02 \\
\hline Fat mass (\%) & & & & & \\
\hline Depressed & 28.59 & 8.76 & 27.59 & 8.11 & 0.0000 \\
\hline Nondepressed & 24.08 & 4.9 & 23.31 & 4.84 & 0.02 \\
\hline Steps/day & & & & & \\
\hline Depressed & $8,646.63$ & $5,887.314$ & II,35।.2। & $7,306.701$ & 0.0000 \\
\hline Nondepressed & $|4,40|$ & $12,825.98$ & 18,442 & 11,915 & 0.02 \\
\hline Energy expenditur & & & & & \\
\hline Depressed & $2,779.78$ & $\mathrm{I}, 518.94$ & $3,066.316$ & I,578.29 & 0.03 \\
\hline Nondepressed & $2,553.286$ & $\mathrm{I}, 242.2 \mathrm{I}$ & $3,345.42$ & I,726.28 & ns \\
\hline
\end{tabular}


Table 2 (Continued)

\begin{tabular}{|c|c|c|c|c|c|}
\hline \multirow[t]{2}{*}{ Parameters } & \multicolumn{2}{|l|}{ Baseline } & \multicolumn{2}{|c|}{3 months } & \multirow[t]{2}{*}{$P$-value } \\
\hline & Median & SD & Median & SD & \\
\hline \multicolumn{6}{|c|}{ Physical activity duration (minutes) } \\
\hline Depressed & 43.36 & 35.01 & 72.26 & 33.07 & 0.0000 \\
\hline Nondepressed & 65 & 28.37 & 89 & 25.05 & 0.0000 \\
\hline \multicolumn{6}{|l|}{ MRC } \\
\hline Depressed & 3.4210 & 0.6924 & 2.2105 & 0.7873 & 0.0000 \\
\hline Nondepressed & 3.28 & 0.75 & 2.14 & 0.69 & 0.004 \\
\hline \multicolumn{6}{|l|}{ BODE index } \\
\hline Depressed & 10.15 & 2.794 & 7.78 & 2.149 & 0.0000 \\
\hline Nondepressed & 9.57 & 3.25 & 7.28 & 2.37 & 0.04 \\
\hline \multicolumn{6}{|l|}{ CAT } \\
\hline Depressed & 19.78 & 3.79 & $|5.2|$ & 3.18 & 0.0000 \\
\hline Nondepressed & 20.42 & 3.45 & 16.14 & 4.09 & 0.001 \\
\hline
\end{tabular}

Abbreviations: 6MWT, 6-minute walk test; BMI, body mass index; BODE, BMI, obstruction, dyspnea, exercise capacity; CAT, COPD Assessment Test; CDT, Clock Drawing Test; CPM, Colored Progressive Matrices; FEV , forced expiratory volume in the Ist second; FVC, forced vital capacity; HADS-A, Hospital Anxiety and Depression Scale, anxiety subscale; HADS-D, Hospital Anxiety and Depression Scale, depression subscale; HAM-D, Hamilton Depression Rating Scale; IC, inspiratory capacity; MRC, Medical Research Council; ns, nonsignificant; RAVLT, Rey Auditory Verbal Learning Test; SCL-90, Symptom Checklist 90; SD, standard deviation; STAI, State-Trait Anxiety Inventory; SVC, slow vital capacity; TMT, Trail Making Test.

(Table 3); the following parameters showed significant improvements:

- HAM-D (D subgroup: 9 \pm 2.19 , ND subgroup: 3.14 \pm 6.20 , $P=0.02)$;

- HADS-A (D subgroup: 3.84 \pm 2.5 , ND subgroup: $1: 42 \pm 1.98, P=0.03)$; and

- SCL-90 (D subgroup: 0.486 \pm 0.287 , ND subgroup: $0.247 \pm 0.177, P=0.05$ ) (Table 3).

A significant correlation between psychometric (in particular, HADS-A, HADS-D, STAI-2, SCL-90, TMT-B, TMT-BA, and CPM) and internistic parameters was found, especially with fat mass and BMI in the total population: the reduction in fat mass and BMI was related to decreased anxiety and depression and improved QoL and cognitive performance (Tables 4 and 5; Figures 3-6).

At baseline in group $\mathrm{D}$, a significant correlation was present between BMI and the following psychometric

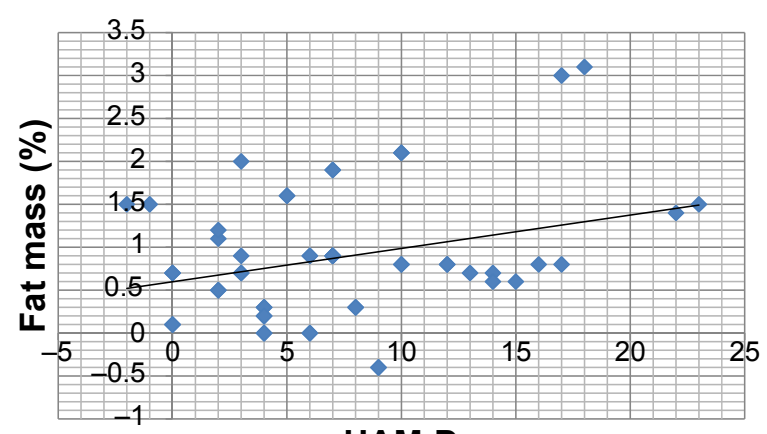

\section{HAM-D}

Figure I Scatterplot of absolute variations of HAM-D and fat mass from baseline to 3 months in the total sample of patients with COPD in a pulmonary rehabilitation program.

Abbreviation: HAM-D, Hamilton Depression Rating Scale. variables: HADS-A $(r=0.47, P=0.04)$; HADS-D $(r=0.5$, $P=0.02) ;$ SCL-90 $(r=0.56, P=0.01)$; STAI-2 $(r=0.51, P=0.02)$; TMT-A $(r=0.52, P=0.02)$; TMT-B $(r=0.44, P=0.05)$; RAVLT $(r=-0.49, P=0.03)$; and CPM $(r=-0.63, P=0.003)$ (Tables 4 and 5; Figures 5 and 6$)$. These correlations were not statistically significant in subgroup ND.

A significant correlation between $\mathrm{BMI}$ and fat mass was present at baseline in subgroup $\mathrm{D}(r=0.8667, P=0.0000)$ but not in subgroup ND ( $r=0.3929, P=0.3833)$.

In subgroup $\mathrm{D}$, the reduction in BMI was significantly related with fat mass $(r=0.6072, P=0.005)$, but the same could not be affirmed for patients of the ND subgroup (Tables 4 and 5).

\section{Discussion}

In agreement with other findings, ${ }^{5,6}$ we found a high prevalence $(73 \%)$ of patients with depressive symptoms

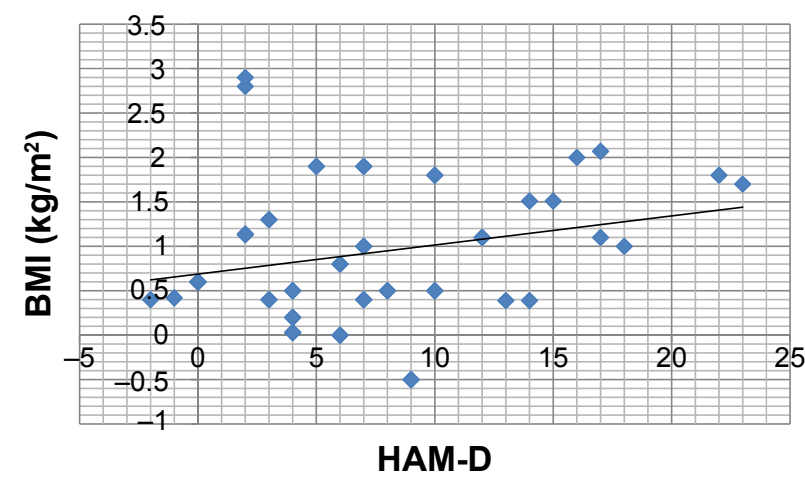

Figure 2 Scatterplot of absolute variations of HAM-D and BMI from baseline to 3 months in the total sample of patients with COPD in a pulmonary rehabilitation program. Abbreviations: BMI, body mass index; HAM-D, Hamilton Depression Rating Scale. 
Table 3 Unpaired comparison analysis of the differences following pulmonary rehabilitative treatment between the D and ND subgroups of patients with COPD

\begin{tabular}{|c|c|c|c|c|c|}
\hline \multirow{2}{*}{$\begin{array}{l}\text { Comparison of variations } \\
\text { between } D \text { and ND subgroups }\end{array}$} & \multicolumn{2}{|c|}{ Variation in subgroup $\mathbf{D}$} & \multicolumn{2}{|c|}{ Variation in subgroup ND } & \multirow[t]{2}{*}{$P$-value } \\
\hline & Median & SD & Median & SD & \\
\hline HAM-D & 9 & 2.19 & 3.14 & 6.20 & 0.02 \\
\hline HADS-A & 3.84 & 2.5 & 1.42 & 1.98 & 0.03 \\
\hline HADS-D & 5.57 & 3.32 & 3.28 & 2.56 & ns \\
\hline STAI-I & 10.6 & 10.33 & 9 & 5.94 & ns \\
\hline STAI-2 & 12 & 9.53 & 8.7 & 7.15 & ns \\
\hline SCL-90 & 0.486 & 0.287 & 0.247 & 0.177 & 0.05 \\
\hline TMT-A & 11.89 & 22.52 & 16.85 & 18.32 & ns \\
\hline TMT-B & 63.21 & 69.49 & 80.57 & 57.82 & ns \\
\hline TMT-BA & 49.21 & 60.97 & 60.85 & 55.98 & ns \\
\hline RAVLT (immediate) & -8.36 & 5.02 & -6.85 & 7.38 & ns \\
\hline RAVLT (deferred) & -1.94 & 1.89 & -2.28 & 2.36 & ns \\
\hline CDT & -1.06 & 1.7 & -1.28 & 1.82 & ns \\
\hline CPM & -4.21 & 3.72 & -4.14 & 5.45 & ns \\
\hline $\mathrm{FVC}(\mathrm{L})$ & -0.28 & 0.27 & -0.49 & 0.34 & ns \\
\hline $\mathrm{FEV}_{1}(\mathrm{~L})$ & -0.19 & 0.21 & -0.11 & 0.13 & ns \\
\hline $\mathrm{FEV}_{1} / \mathrm{FVC}(\%)$ & -0.94 & 4.80 & 3.85 & 7.60 & ns \\
\hline SVC (L) & -0.30 & 0.33 & -0.17 & 0.11 & ns \\
\hline IC (L) & -0.28 & 0.3 & -0.56 & 0.82 & ns \\
\hline 6MWT (m) & -94.57 & 63.25 & -87.85 & 63.69 & ns \\
\hline BMI $\left(k g / m^{2}\right)$ & 0.9 & 0.74 & 1.02 & 0.93 & ns \\
\hline Fat mass (\%) & 1 & 0.76 & 0.77 & 0.68 & ns \\
\hline Steps/day & -286.5 & 533.09 & -792.142 & I,389.5 & ns \\
\hline Energy expenditure (kcal/3 days) & -108.52 & 75.23 & -173 & 189.25 & ns \\
\hline Physical activity duration (minutes) & -28.89 & 12.09 & -24.28 & 5.15 & ns \\
\hline MRC & 1.21 & 0.41 & 1.14 & 0.69 & ns \\
\hline BODE index & 2.36 & 1.11 & 2.14 & 2.19 & ns \\
\hline CAT & 4.57 & 1.67 & 4.28 & 2.13 & ns \\
\hline
\end{tabular}

at baseline in our COPD subjects that showed a significant decrease at the end of the rehabilitation program (7.7\%). Previous reviews on pulmonary rehabilitation have indicated that 4-week programs can improve fatigue and emotional function, but these reviews included trials that did not specifically address effects on anxiety and depression, ${ }^{36,46}$ while in our results, the mean HAM-D scores (used in our research to divide the whole population into the two subgroups and for the evaluation of the changes of depressive symptoms) decreased significantly both in the total sample and in the D and ND subgroups.

Another study examined the relationship between depression and aerobic exercise in generic chronic illness patients; ${ }^{47}$ some others found a correlation between depression and/or anxiety and aerobic exercise in COPD patients undergoing pulmonary rehabilitation, but they did not investigate variables such as BMI or obesity. ${ }^{36,48-51}$
Moreover, in our trial, all other assessed psychiatric (depression, anxiety, and cognitive function) and medical/ pneumological parameters demonstrated a significant improvement after the rehabilitation program.

The evaluation of cognitive performances, improved at 3 months, showed some peculiarities: the improvement in visual-spatial attention (TMT-A), although significant, was modest if compared with the TMT-B parameter, which assesses attention shifting ability and visual-spatial attention, as summarized by TMT-BA that represents the difference between the times of part B and those of part A in executive functioning (Table 1).

Memory, assessed by RAVLT, was significantly enhanced at 3 months both in immediate and in deferred recall (Table 1), such as praxic skills, mental representation, and planning (assessed by CDT) and deduction skills (evaluated through CPM) (Table 1). 


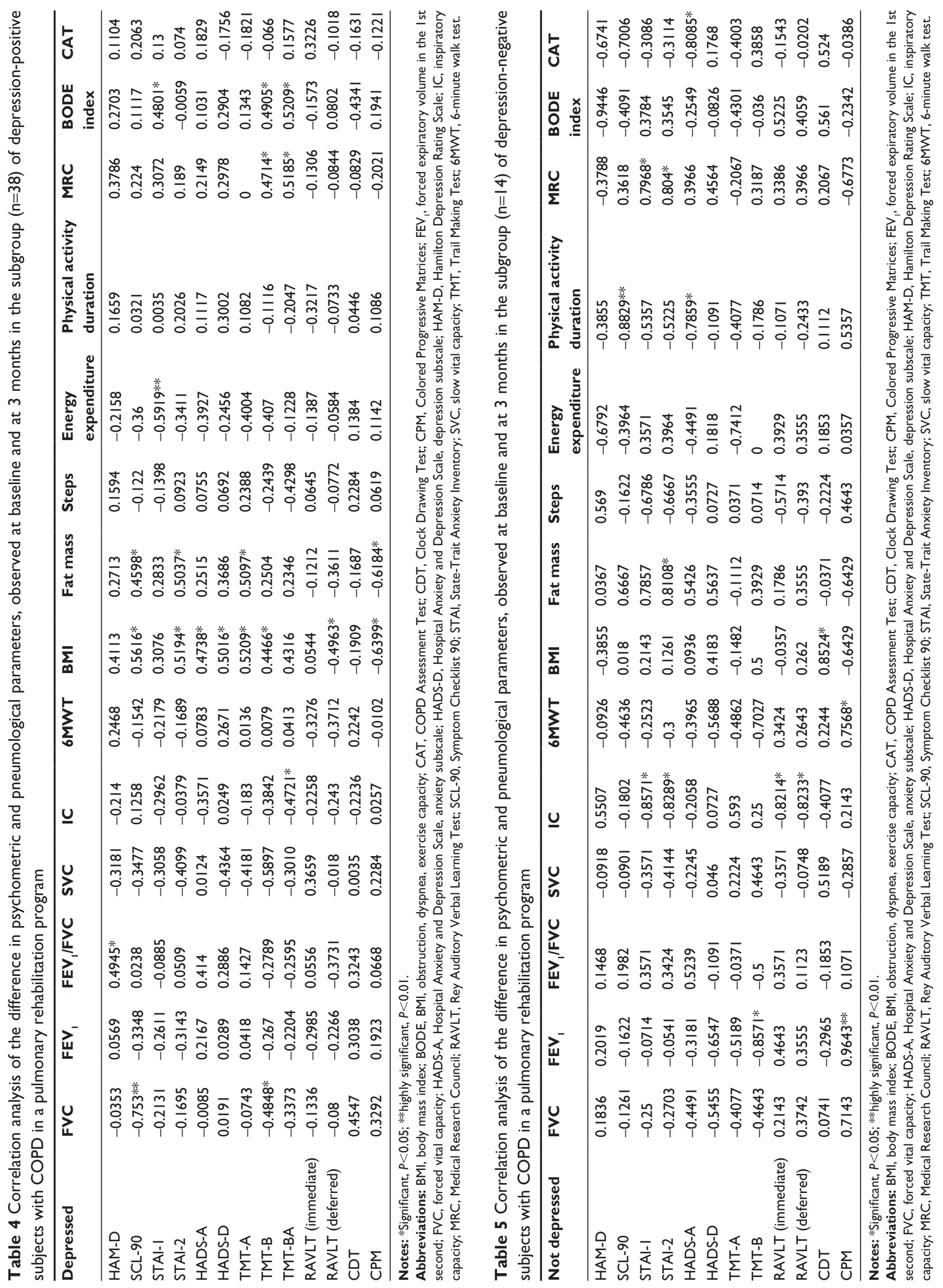




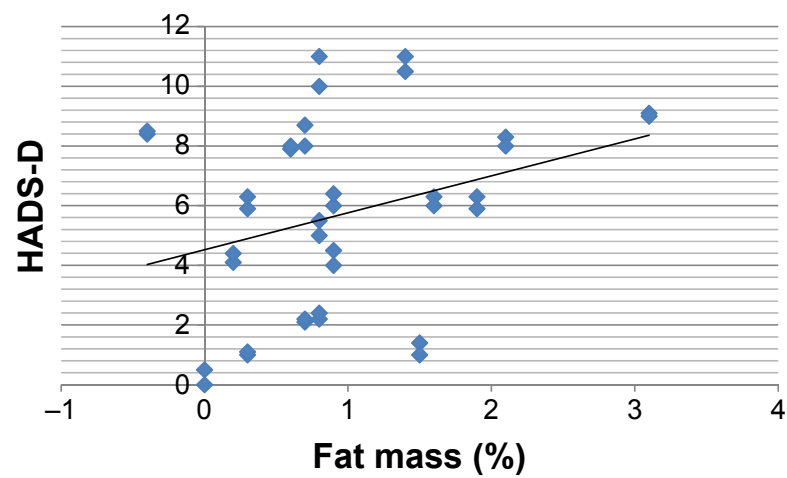

Figure 3 Scatterplot of absolute variations of fat mass and HADS-D from baseline to 3 months in the depression-positive subgroup of patients with COPD in a pulmonary rehabilitation program.

Abbreviation: HADS-D, Hospital Anxiety and Depression Scale, depression subscale.

We highlight the interesting correlations among STAI-1, MRC, and BODE (BMI, obstruction, dyspnea, exercise capacity) index: decrease in anxiety correlated with the improvement of dyspnea (MRC) and BODE index in the absence of correlation with objective indices such as forced expiratory volume in the 1st second, BMI, and 6MWT; this fact could be explained by the tendency of anxious depressed patients to amplify dyspnea. ${ }^{52}$

The improvement in psychological parameters (anxiety and depressive symptoms, QoL, and cognitive performances) was related to a general decrease of fat mass and BMI in the total sample (Tables 4 and 5). In subgroup D, this correlation was particularly evident between BMI and the following psychometric variables: HADS-A, HADS-D, SCL-90, STAI-2, TMT-A, TMT-B, RAVLT, and CPM (Table 4). Despite the general decrease of fat mass and BMI in the total sample, it was not statistically significant in subgroup ND, for which, unlike subgroup D (Table 5), there was no correlation between BMI and fat mass, both at baseline and

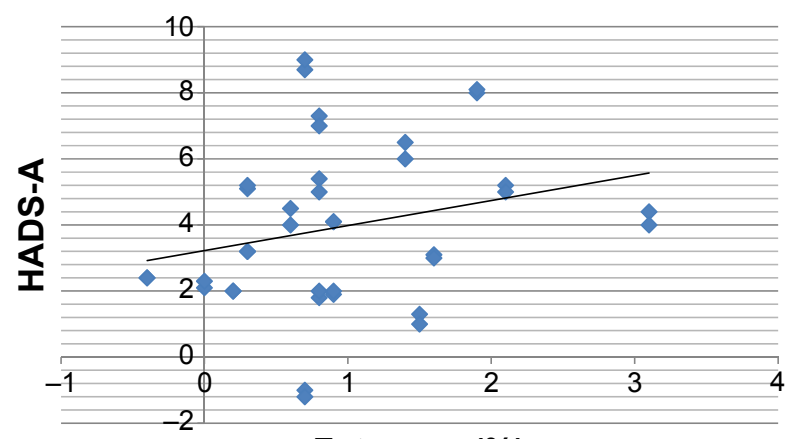

Fat mass (\%)

Figure 4 Scatterplot of absolute variations of fat mass and HADS-A from baseline to 3 months in the depression-positive subgroup of patients with COPD in a pulmonary rehabilitation program.

Abbreviation: HADS-A, Hospital Anxiety and Depression Scale, anxiety subscale.

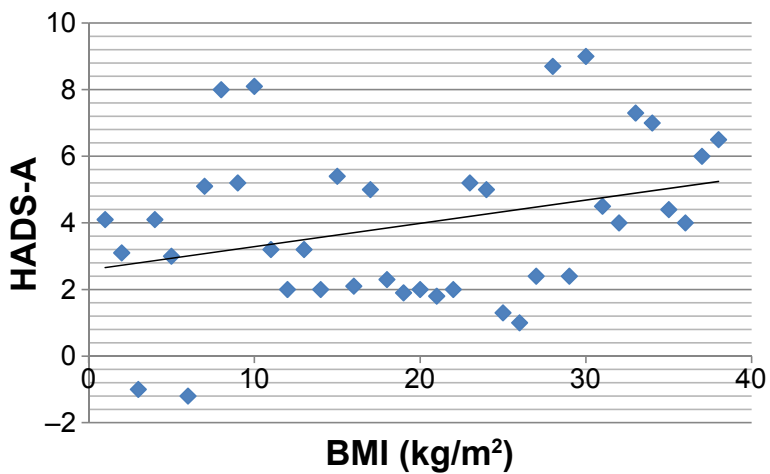

Figure 5 Scatterplot of absolute variations of BMI and HADS-A from baseline to 3 months in the depression-positive subgroup of patients with COPD in a pulmonary rehabilitation program.

Abbreviations: BMI, body mass index; HADS-A, Hospital Anxiety and Depression Scale, anxiety subscale.

after the rehabilitation program. In this sense, BMI alone could be insufficient to explain the correlation with psychopathological parameters.

The different results observed between the two subgroups could be explained by the fact that D-subgroup patients presented a baseline condition of "overweight" and a higher fat mass percentage, not recorded in the ND subgroup, which was mainly composed of persons of normal weight. The only factor that indeed correlated with the majority of psychometric parameters was BMI, but only in subgroup $\mathrm{D}$, where we recorded a correlation between BMI and fat mass.

In spite of the interesting findings, at least three limitations must be considered. First, metabolic and neurobiological analysis (eg, inflammatory and oxidative markers) could explain the link between anxiety and depressive symptoms and internistic medical disorders, such as COPD, in order to define a new meaning and management of them, but in this study was not performed. Second, the lack of

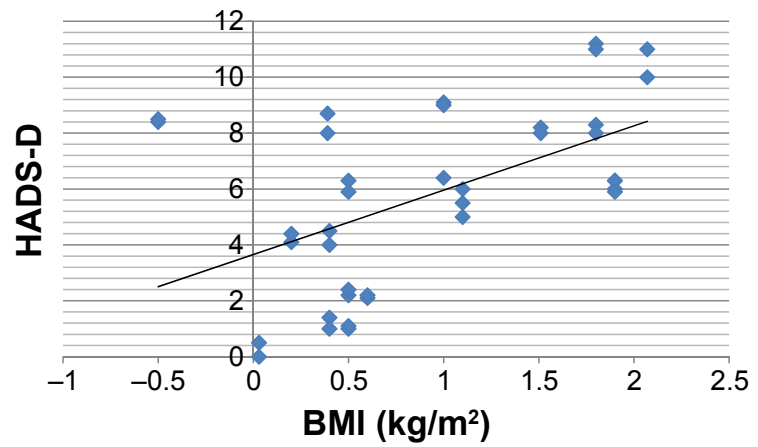

Figure 6 Scatterplot of absolute variations of BMI and HADS-D from baseline to 3 months in the depression-positive subgroup of patients with COPD in a pulmonary rehabilitation program.

Abbreviations: BMI, body mass index; HADS-D, Hospital Anxiety and Depression Scale, depression subscale. 
muscle mass evaluation could influence depressive and anxious symptoms. ${ }^{53}$ Third, our sample size was small. So further studies are needed to evaluate the link between psychopathological symptoms and COPD in terms of inflammatory and oxidative markers with specific measures of them and the impact of muscle wasting on depression and anxiety in this specific population and, at the end, to augment the power of statistical analysis.

\section{Conclusion}

Our results suggest that it might be useful, in the context of multiple chronic diseases, to start a specific rehabilitation program (eg, of aerobic exercise) in order to establish a more appropriate and integrated therapeutic approach where there is suspicion, that needs to be confirmed, that a condition of increased adiposity could influence the genesis and evolution of psychiatric disorders.

\section{Acknowledgment}

The authors thank Professor Filippo Palermo (University of Catania) for his support in statistical analysis.

\section{Disclosure}

The authors report no conflicts of interest in this work and have received no payment in the preparation of this manuscript.

\section{References}

1. Murray CJ, Lopez AD. Alternative projections of mortality and disability by cause 1990-2020: Global Burden of Disease Study. Lancet. 1997;349:1498-1504.

2. Lopez AD, Murray CC. The global burden of disease, 1990-2020. Nat Med. 1998;4:1241-1243.

3. Celli BR, Pauwels R, Snider GL. Definition, diagnosis and staging. In: Standards for the Diagnosis and Management of Patients with COPD. New York: American Thoracic Society; Lausanne: European Respiratory Society; 2004:8-13.

4. Janson C, Björnsson E, Hetta J, Boman G. Anxiety and depression in relation to respiratory symptoms and asthma. Am J Respir Crit Care Med. 1994;149:930-934.

5. Di Marco F, Verga M, Reggente M, et al. Anxiety and depression in COPD patients: the roles of gender and disease severity. Respir Med. 2006;100(10):1767-1774.

6. van Manen JG, Bindels PJ, Dekker FW, IJzermans CJ, van der Zee JS, Schadé E. Risk of depression in patients with chronic obstructive pulmonary disease and its determinants. Thorax. 2002;57:412-416.

7. Ormel J, Kempen GI, Deeg DJ, Brilman EI, van Sonderen E, Relyveld J. Functioning, well-being, and health perception in late middle-aged and older people: comparing the effects of depressive symptoms and chronic medical conditions. J Am Geriatr Soc. 1998;46:39-48.

8. Stage KB, Middelboe T, Stage TB, Sørensen CH. Depression in COPDmanagement and quality of life considerations. Int $J$ Chron Obstruct Pulmon Dis. 2006;1(3):315-320.

9. Schane RE, Walter LC, Dinno A, Covinsky KE, Woodruff PG. Prevalence and risk factors for depressive symptoms in persons with chronic obstructive pulmonary disease. J Gen Intern Med. 2008;23(11):1757-1762.
10. Boden JM, Fergusson DM, Horwood LJ. Cigarette smoking and depression: tests of causal linkages using a longitudinal birth cohort. Br J Psychiatry. 2010;196:440-446.

11. DelMastro K, Hellem TL, Kim N, Kondo D, Sung YH, Renshaw PF. Incidence of major depressive episode correlates with elevation of substrate region of residence. J Affect Disord. 2011;129: 376-379.

12. Janssen DJ, Spruit MA, Leue C, et al; Ciro network. Symptoms of anxiety and depression in COPD patients entering pulmonary rehabilitation. Chron Respir Dis. 2010;7(3):147-157.

13. Kocabas A, Tezcagirir G, Seydaoglu G, Ozyilmaz E. The relationship between comorbidities and systemic inflammation in patients with COPD. Eur Respir J. 2011;38(Suppl 55):4057.

14. Fabbri LM, Rabe KF. From COPD to chronic systemic inflammatory syndrome? Lancet. 2007;370:797-799.

15. Jeffery PK, Laitinen A, Venge P. Biopsy markers of airway inflammation and remodelling. Respir Med. 2000;94 Suppl F:S9-S15.

16. Yanbaeva DG, Dentener MA, Spruit MA, et al. IL6 and CRP haplotypes are associated with COPD risk and systemic inflammation: a casecontrol study. BMC Med Genet. 2009;10:23.

17. Yende S, Waterer GW, Tolley EA, et al. Inflammatory markers are associated with ventilatory limitation and muscle dysfunction in obstructive lung disease in well functioning elderly subjects. Thorax. 2006; 61(1):10-16.

18. Gan WQ, Man SF, Senthilselvan A, Sin DD. Association between chronic obstructive pulmonary disease and systemic inflammation: a systematic review and a meta-analysis. Thorax. 2004;59(7): 574-580.

19. Haddad F, Zaldivar F, Cooper DM, Adams GR. IL-6-induced skeletal muscle atrophy. J Appl Physiol (1985). 2005;98(3):911-917.

20. Langen RC, Schols AM, Kelders MC, Van Der Velden JL, Wouters EF, Janssen-Heininger YM. Tumor necrosis factor-alpha inhibits myogenesis through redox-dependent and -independent pathways. Am J Physiol Cell Physiol. 2002;283(3):C714-C721.

21. Potashkin JA, Meredith GE. The role of oxidative stress in the dysregulation of gene expression and protein metabolism in neurodegenerative disease. Antioxid Redox Signal. 2006;8:144-151.

22. Dantzer R. Cytokine, sickness behavior, and depression. Immunol Allergy Clin North Am. 2009;29:247-264.

23. Hohagen F, Timmer J, Weyerbrock A, et al. Cytokine production during sleep and wakefulness and its relationship to cortisol in healthy humans. Neuropsychobiology. 1993;28(1-2):9-16.

24. Lehto SM, Huotari A, Niskanen L, et al. Serum IL-7 and G-CSF in major depressive disorder. Prog Neuropsychopharmacol Biol Psychiatry. 2010;34(6):846-851.

25. del Rey A, Furukawa H, Monge-Arditi G, Kabiersch A, Voigt KH, Besedovsky HO. Alterations in the pituitary-adrenal axis of adult mice following neonatal exposure to interleukin-1. Brain Behav Immun. 1996; 10(3):235-248.

26. Shelton RC, Miller AH. Eating ourselves to death (and despair): the contribution of adiposity and inflammation to depression. Prog Neurobiol. 2010;91:275-299.

27. Franssen FM, O'Donnell DE, Goossens GH, Blaak EE, Schols AM. Obesity and the lung: 5. Obesity and COPD. Thorax. 2008;63: $1110-1117$.

28. Capuron L, Miller AH. Immune system to brain signaling: neuropsychopharmacological implications. Pharmacol Ther. 2011;130: 226-238.

29. Eyre H, Baune BT. Neuroimmunological effects of physical exercise in depression. Brain Behav Immun. 2012;26:251-266.

30. Nici L, Donner C, Wouters E, et al; ATS/ERS Pulmonary Rehabilitation Writing Committee. American Thoracic Society/European Respiratory Society statement on pulmonary rehabilitation. Am JRespir Crit Care Med. 2006;173(12):1390-1413.

31. Babyak M, Blumenthal JA, Herman S, et al. Exercise treatment for major depression: maintenance of therapeutic benefit at 10 months. Psychosom Med. 2000;62(5):633-638. 
32. Moore KA, Blumenthal JA. Exercise training as an alternative treatment for depression among older adults. Altern Ther Health Med. 1998; 4:48-56.

33. Rose C, Wallace L, Dickson R, et al. The most effective psychologicallybased treatments to reduce anxiety and panic in patients with chronic obstructive pulmonary disease (COPD): a systematic review. Patient Educ Couns. 2002;47(4):311-318.

34. Klein MH, Greist JH, Gurman AS, et al. A comparative outcome study of group psychotherapy vs exercise treatments for depression. Int J Ment Health. 1984-1985;13:148-176.

35. Martinsen EW, Hoffart A, Solberg O. Comparing aerobic with nonaerobic forms of exercise in the treatment of clinical depression: a randomized trial. Compr Psychiatry. 1989;30:324-331.

36. Coventry PA, Bower P, Keyworth C, et al. The effect of complex interventions on depression and anxiety in chronic obstructive pulmonary disease: systematic review and meta-analysis. PLoS One. 2013; 8(4):e60532.

37. ZuWallack R, Hashim A, McCuskerC, Normandin E, Benoit-Connors ML, Lahiri B. The trajectory of change over multiple outcome areas during comprehensive outpatient pulmonary rehabilitation. Chron Respir Dis. 2006;3(1):11-18.

38. Nici L, ZuWallack R, Wouters E, Donner CF. On pulmonary rehabilitation and the flight of the bumblebee: the ATS/ERS Statement on Pulmonary Rehabilitation. Eur Respir J. 2006;28(3):461-462.

39. Ries AL, Kaplan RM, Limberg TM, Prewitt LM. Effects of pulmonary rehabilitation on physiologic and psychosocial outcomes in patients with chronic obstructive pulmonary disease. Ann Intern Med. 1995; 122(11):823-832.

40. Griffiths TL, Burr ML, Campbell IA, et al. Results at 1 year of outpatient multidisciplinary pulmonary rehabilitation: a randomised controlled trial. Lancet. 2000;355(9201):362-368.

41. Lacasse Y, Wong E, Guyatt GH, King D, Cook DJ, Goldstein RS. Metaanalysis of respiratory rehabilitation in chronic obstructive pulmonary disease. Lancet. 1996;348(9035):1115-1119.

42. Derom E, Marchand E, Troosters T. Pulmonary rehabilitation in chronic obstructive pulmonary disease. Ann Readapt Med Phys. 2007;50: 615-626.

43. Wang J, Thornton JC, Russell M, Burastero S, Heymsfield S, Pierson RN Jr. Asians have lower body mass index (BMI) but higher percent body fat than do whites: comparisons of anthropometric measurements. Am J Clin Nutr. 1994;60(1):23-28.
44. Wouters EFM, ZuWallack R, Lareau SC. Management of stable COPD: pulmonary rehabilitation. In: Standards for the Diagnosis and Management of Patients with COPD. New York: American Thoracic Society; Lausanne: European Respiratory Society; 2004:100-112.

45. World Health Organization. Obesity and Overweight. Fact sheet no 311. Geneva: World Health Organization; 2015. Available from: http:// www.who.int/mediacentre/factsheets/fs311/en/. Accessed November $20,2015$.

46. Lacasse Y, Goldstein R, Lasserson TJ, Martin S. Pulmonary rehabilitation for chronic obstructive pulmonary disease. Cochrane Database Syst Rev. 2006;(4):CD003793.

47. Herring MP, Puetz TW, O’Connor PJ, Dishman RK. Effect of exercise training on depressive symptoms among patients with a chronic illness: a systematic review and meta-analysis of randomized controlled trials. Arch Intern Med. 2012;172(2):101-111.

48. Paz-Díaz H, Montes de Oca M, López JM, Celli BR. Pulmonary rehabilitation improves depression, anxiety, dyspnea and health status in patients with COPD. Am J Phys Med Rehabil. 2007;86(1):30-36.

49. Garuti G, Cilione C, Dell'Orso D, et al. Impact of comprehensive pulmonary rehabilitation on anxiety and depression in hospitalized COPD patients. Monaldi Arch Chest Dis. 2003;59(1):56-61.

50. Tselebis A, Bratis D, Pachi A, et al. A pulmonary rehabilitation program reduces levels of anxiety and depression in COPD patients. Multidiscip Respir Med. 2013;8(1):41.

51. Bhandari NJ, Jain T, Marolda C, ZuWallack RL. Comprehensive pulmonary rehabilitation results in clinically meaningful improvements in anxiety and depression in patients with chronic obstructive pulmonary disease. J Cardiopulm Rehabil Prev. 2013;33(2):123-127.

52. Ramasamy R, Hildebrandt T, O'Hea E, et al. Psychological and social factors that correlate with dyspnea in heart failure. Psychosomatics. 2006;47(5):430-434.

53. Vanfleteren LE, Spruit MA, Groenen M, et al. Clusters of comorbidities based on validated objective measurements and systemic inflammation in patients with chronic obstructive pulmonary disease. Am J Respir Crit Care Med. 2013;187(7):728-735.
International Journal of COPD

\section{Publish your work in this journal}

The International Journal of COPD is an international, peer-reviewed journal of therapeutics and pharmacology focusing on concise rapid reporting of clinical studies and reviews in COPD. Special focus is given to the pathophysiological processes underlying the disease, intervention programs, patient focused education, and self management protocols.

\section{Dovepress}

This journal is indexed on PubMed Central, MedLine and CAS. The manuscript management system is completely online and includes a very quick and fair peer-review system, which is all easy to use. Visit http://www.dovepress.com/testimonials.php to read real quotes from published authors. 